\title{
What Makes a City Liveable? Implications For Next- Generation Infrastructure Services
}

\author{
J.M. Leach ${ }^{\mathrm{a}^{*}}$ \\ S.E. Lee ${ }^{\mathrm{a}}$ \\ P.A. Braithwaite \\ C.J. Bouch ${ }^{\mathrm{a}}$ \\ N. Grayson ${ }^{\mathrm{b}}$ \\ C.D.F. Rogers ${ }^{\mathrm{a}}$
}

\begin{abstract}
Infrastructure forms the framework within which modern societies operate both at the physical and social level. It includes (amongst others) digital, green and social infrastructures, emergency services and food networks, water, energy, waste and transport. Infrastructure, by its very nature, locks in behaviours. The Liveable Cities research consortium aims to identify and test radical engineering interventions that will lead to future low carbon, resource secure cities in which societal wellbeing is prioritised, and these will necessarily influence the shape of infrastructure provision. This paper presents a discussion of what comprises a liveable city and how it might be achieved. It presents the City Design Framework, a technique for the analysis of city strategies that establishes a hierarchy of needs relevant to successfully achieving a liveable city. The framework supports changing perceptions of infrastructure since the necessary future changes have the potential to radically alter people's lifestyle and wellbeing.
\end{abstract}

\section{Key words: Liveability; Liveable city; Sustainability; City design; Strategic management; Infrastructure planning; Performance parameters.}

\section{Introduction}

Cities need to be sustainable, which broadly means living within what the biosphere can provide and (in terms of wastes and emissions) absorbing without overburdening future natural resources, and resilient, in that it continues to function in the face of (radical) change. Moreover, wellbeing and quality of life is highly valued and should be ensured for all in the future. The adjective increasingly used to capture these aspirations is 'liveable'. The world is facing considerable challenges in realising these liveable aspirations and it is widely accepted that there is an imperative to act quickly if even more serious consequences are to be avoided in the future - current ways of living are already storing up serious future consequences. Accordingly, Liveable Cities, a 5-year research programme, combining the Universities of Birmingham,

${ }^{a}$ Civil Engineering, University of Birmingham, Birmingham, B15 2TT.

${ }^{\mathrm{b}}$ Birmingham City Council, Birmingham, B1 1BR, UK.

*Corresponding author: Joanne Leach j.leach@bham.ac.uk http://dx.doi.org/10.14453/isngi2013.proc.29 
Lancaster, Southampton and University College London (UCL) and funded by the Engineering and Physical Sciences Research Council (EPSRC), was established in 2012 to identify and test radical engineering interventions that will lead to liveable cities of the future. The focus of this programme concerns pathways to low-carbon, resource-secure cities in which societal wellbeing is prioritised, while changes in population, demography, climate, security of energy/other resources, and a plethora of historical legacies, provide the context ${ }^{1}$.

In order to bring about appropriate changes, it is important first to understand how cities function and how well they perform. This provides a baseline against which to identify and prioritise aspects that would benefit from change and assess the impact of interventions. Accepting that cities are enormously complex and individual in nature, there is a need nevertheless to establish a framework in which the most important indicators of functional performance can be described and assessed. The approach taken by Liveable Cities, and reported herein, is to view cities through a comprehensive set of different disciplinary lenses covering social, environmental and economic perspectives, distil from these views sets of performance parameters that describe how cities and their citizens operate, and capture them in a bespoke framework. The framework adopted is derived from a classical strategic framework that links visions through aims and objectives, and then strategies and policies, to processes and actions $-\mathrm{a}$ City Design Framework (CDF). This can then be applied to any city and its context by analysing its visions, formal and informal policies, strategy documents, de facto strategies and practices to fill in the gaps in the framework and then, via datasets and models, explore its performance both before and after interventions. While this process is conceptually straightforward, the implementation of change relies upon a fit to the context, exogenous and endogenous influences and city capacity and capability, and faces many barriers, such as resistance to individual and societal behaviour change, political will to enact change in a climate of short-term electoral cycles, professional inertia, the capability and capacity to effect changes and the perceived risks associated with doing things differently. Nevertheless it has the potential to make explicit the opportunities and consequences of action or inaction.

\section{What is urban liveability?}

Dictionary and thesaurus definitions of liveability indicate that liveability is about being suitable for (usually) human living $2,3,4,5$. These definitions suggest a basic level of suitability, tolerability and functionality that is at increasing odds with the use of the word when applied to cities. In relation to cities, liveability describes the surpassing of basic living conditions to meet aspirations. This is reflected in the annual rankings of liveable cities by (separately) the Economist's Intelligence Unit, Mercer and Monocle ${ }^{6,7,8}$.

This paper is concerned with the liveability of cities from the UK perspective and how centres of population can be developed to ensure improved liveability. Infrastructure provides the structures and mechanisms through which cities function at their most basic: energy water, waste, etc. Infrastructure also provides the structures and mechanisms though which cities function at their most sophisticated: ICT, integrated public transport, low carbon energy, re-use and recycling, sustainable communities, etc. Thus infrastructure is crucial in achieving urban liveability. 
Liveability is almost inextricably linked to the sustainability of cities. In fact, Portney ${ }^{9}$ maintains that, as concepts, liveability and sustainability are practically indistinguishable. In practice, however, a sustainable city is not de-facto liveable and a liveable city is not de-facto sustainable. Despite, or perhaps because of, extensive writings and reflections on sustainability and liveability their meanings remain, as they did at the time of Portney's writing, nebulous and open to a myriad of interpretations. This paper proposes that liveability and sustainability can, and should, be inextricably intertwined, incorporating societal and planetary wellbeing within the context of low carbon living and resource security.

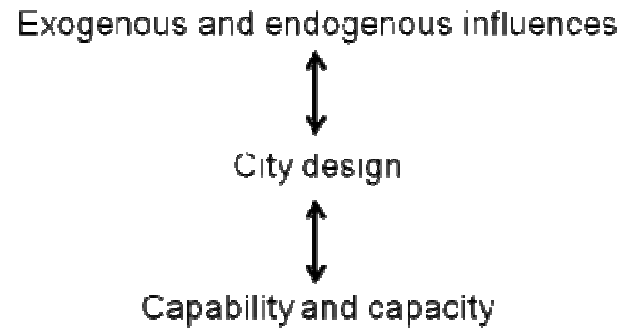

Figure 1. Influences upon city design, adapted from Foundation for Global Education and Research $^{17}$

\section{Factors to Consider when Designing a Liveable City}

This paper proposes a framework that allows cities to design for liveability as defined above (perhaps best termed a 'common challenge') whilst at the same time addressing bespoke challenges specific to themselves (often arising from their local context). Cities must be cognisant of and responsive to exogenous and endogenous influences (including global trends such as climate change, systemic rules such as governance systems and available resources such as natural capital), and its own capabilities and capacities (see Figure 1). Cities are bespoke entities, closely coupled to their immediate surroundings. One-size-fits-all solutions are not an option.

\section{A Framework for Designing a Liveable City}

It is convenient to think of the city design process in three stages:

1) Knowing what the city wants to be like in the future

2) Knowing what the city is like now

3) Knowing how to get from how the city is now to how it wants to be in the future

\section{Knowing what the city wants to be like in the future:}

Envisioning the future is no easy feat, not least because the only certainty is that all predictions of what the future will be like will, in one respect or another, be wrong. Once a vision for a city's future has been agreed it must be put into operation. The strategic management literature provides a useful approach. The strategic management hierarchy ${ }^{10,11}$ is represented by a 
triangle that is horizontally sliced into discrete sections that increasingly deconstruct a vision. Figure 2 describes a strategic management hierarchy for a single city. Each layer reflects a level of decision-making, deconstructs the layer above, feeds the layer below and provides feedback for the layer above.

The 'city-wide purpose' comprises the city's vision, aims and objectives and considers the city as a whole unit. The city's vision statement is at the top, of the triangle and is the least detailed element. A vision statement is a high-level, aspirational statement of what success looks like. It is not, and should not be, measurable ${ }^{12}$. Many cities will, in fact, have multiple (or multipart) visions of the future, which may or may not be mutually supportive or cohesive. For example, the vision to be economically vibrant with a focus on advanced manufacturing may well render a low carbon vision difficult and potentially introduce additional barriers to liveability beyond those currently in existence.

This paper proposes the following vision for a liveable UK city: it will be a low carbon, sustainable city providing the highest quality of life with the highest resource security. The vision is deconstructed into a handful of aims: statements that elucidate the core elements of the vision. Aims are the high-level activities that will achieve the vision and, like the vision, are not directly measurable. With regard to liveability, suitable aims for a UK city would be:

- Minimise operational and embodied carbon

- Be resource secure

- Maximise individual and community wellbeing

- Maximise ecosystem services

- Be economically viable

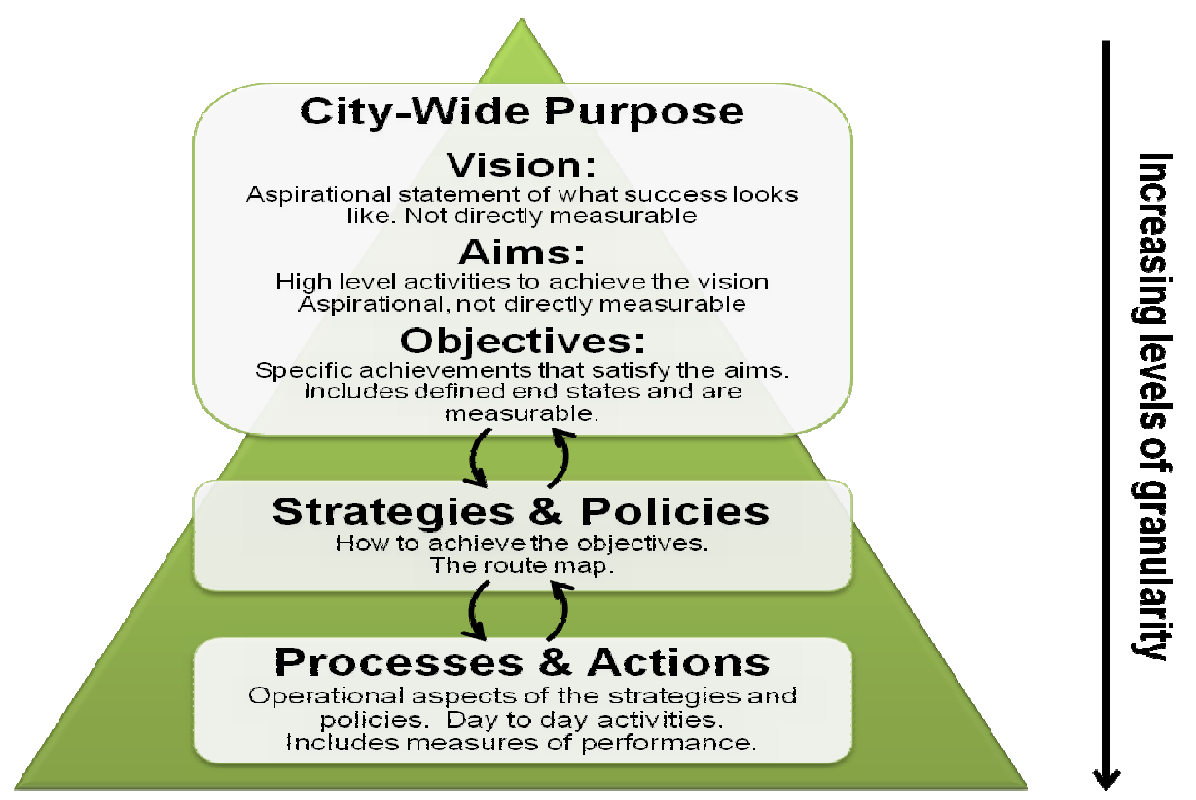

Figure 2. City Strategic Management Hierarchy adapted from Bordum ${ }^{10}$ and Bititci, Carrie and McDevitt $^{11}$ 
Each aim is further deconstructed into objectives that contribute directly to the success of a particular aim. Given that cities work across departments on programs, objectives can be 'less SMART': less specific, less measurable and less accurately timelined, but still achievable and realistic $^{13}$. There should be enough objectives to address all priority elements of each aim, but not so numerous that they become unwieldy. For the aim of minimising operational and embodied carbon suitable objectives might be:

- Reduce energy use from carbon fuels by $80 \%$ (from 1990 levels) by 2050

- Reduce potable water use to 60 liters per person per day by 2050

- Eradicate solid waste to landfill so all solid waste is re-used or recycled by 2050

The relationship between aims and objectives can be 'first order', meaning that any given objective contributes directly to the achievement of its related aim. The objective may also contribute indirectly (a second order relationship) to other aims, but its primary purpose is to achieve its related aim. First order relationships form a critical path to success.

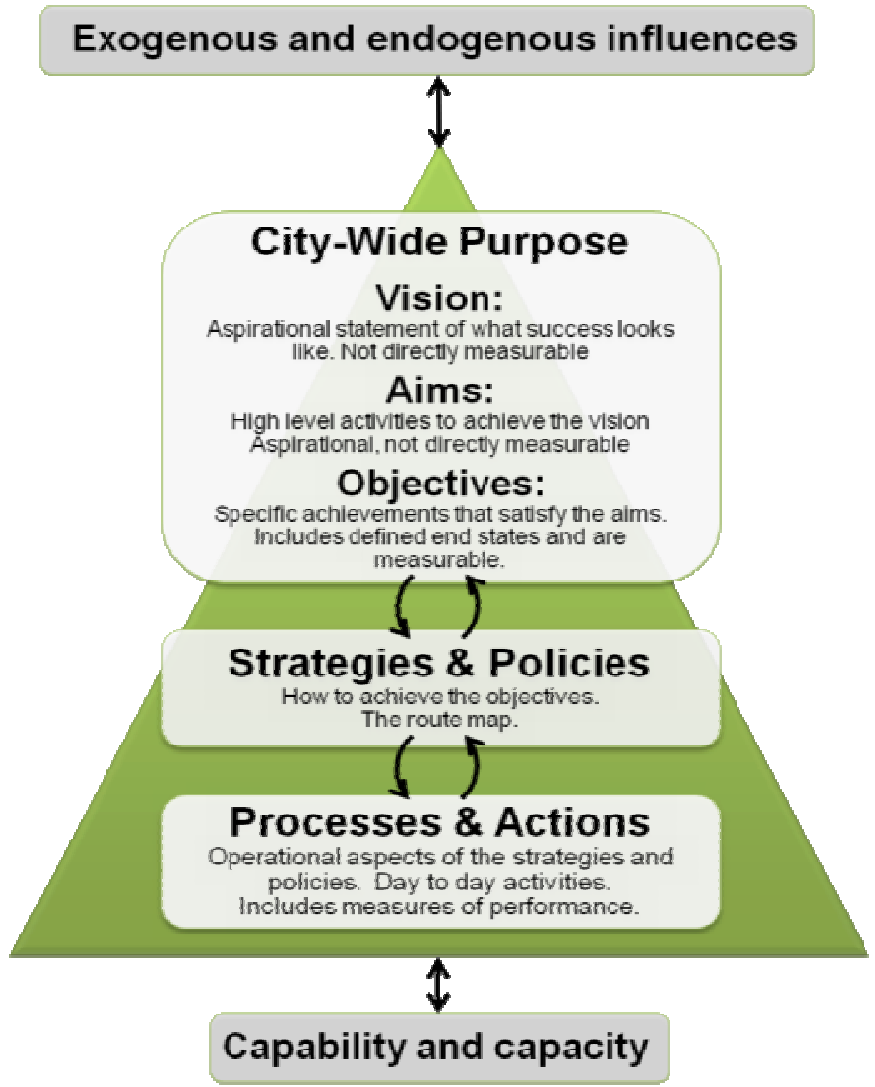

Figure 3. City Design Framework 
Following the hierarchy down to the next level sees the development of strategies and policies to achieve the objectives. It is as important at this level as it was at the objectives level to ensure that first order relationships exist between the strategies and policies and the objectives. Second and even third order relationships should also exist. Together with the first order relationships they form a network of activities that increases the overall resilience of the strategic management hierarchy as well as of any one strategy or policy. Indeed, a network approach should be repeated throughout the hierarchy for this very reason.

Strategies and policies are the statements of how to achieve the objectives. They provide a level of detail that is sufficient to understand the important aspects, end states and targets required achieving each outcome without becoming mired in the operational detail of the day-today processes and actions required, which is reserved for the next level of the hierarchy: processes and actions.

Performance measures at the operational level (processes and actions) must be SMART: specific, measurable, achievable, realistic, and timelined ${ }^{13}$. They should consist of two elements: (1) movement towards achieving the stated targets and (2) understanding the city's functions. Indicators are useful, and frequently used, to measure performance. Indicators alone, however, are not sufficient to understand how a city is actually functioning. What is required is a deeper understanding of operations, which can be achieved through material and energy flow analyses. It is here that the intended and unintended consequences of activities at each level of the hierarchy upon the workings of the city can be elucidated.

The City Strategic Management Hierarchy (Figure 2) can now be brought together with the influences upon city design (Figure 1) to form a framework for city design (Figure 3).

\section{Knowing what the city is like now:}

Success is dependent upon the city having a clear understanding of where it is now so that it can align its current design to its desired design (in this case a design for liveability). This alignment should take place as quickly as possible so that all future activity can be put into moving the city towards its long-term liveable vision. In practice, however, it will be necessary to accept that some policies, strategies or activities that do not fit the overall vision will need to be accommodated for various reasons, for example they may be political, reactionary or urgently required interventions. Such policies, strategies and activities need to be recognised as outside the liveable city vision and invested in appropriately in terms of money, associated disruption and lifespan of the intervention.

\section{Knowing how to get from how the city is now to how it wants to be in the future:}

Over time strategies and policies and processes and actions will need to be reviewed and revised to accommodate progress towards the vision and changing contexts. The rate of change depends upon the nature of the element in question. Some infrastructure, such as housing stock, roads and rail can be in place for more than 100 years. Other infrastructure, such as high speed 
fiber optics, may not be relevant for more than five years. In this context it might be helpful to define timescales: short-term (two to five years), medium-term (30 years) and long-term (50 to 100 years). Figure 4 illustrates these time horizons as applied to the City Design Framework, forming the basis for a roadmap.

\section{Implications for Infrastructure}

Infrastructure can be defined in a variety of ways. In the UK infrastructure is generally agreed to include energy, water, communications, transportation and waste. The Cabinet Office ${ }^{14}$ lists nine sectors of UK infrastructure (each having sub-sectors): energy (including heat networks), water (including water resources and flood defense), communications, transportation, food, emergency services, health care, financial services and government. This services conception of infrastructure can be broadened again to incorporate a systems approach that includes: interdependencies, the effect of the quality of infrastructure upon the national offering (how much more attractive is the UK if it has good infrastructure), societal impacts and green infrastructure that delivers ecosystem services. However it is in this statement that conflict of scales becomes apparent, since infrastructure is conceived variously at an international, national, regional, city and sub-city scale; for a city it is a question of those that are wholly contained plus linkages to beyond city boundaries.

Infrastructure underpins urban liveability, where liveability is defined as societal and planetary wellbeing within the context of low carbon living and resource security. It does this in well-understood ways, providing the structures and mechanisms required for a city to function (see the above lists of resources and other services). Infrastructure also underpins liveability in less well understood ways by providing the building blocks upon which cities flourish. Perhaps the best example of this is the building of the London sewers that led to improved urban environment and citizen health, making London a highly desirable place to live and conduct business and arguably enabling it to become the mega-city it is today ${ }^{15}$; it would be possible to capture this in the CDF. More problematic is the current debate in England about the viability of the proposed High Speed 2 (HS2) rail link connecting London with the Midlands (Birmingham) and eventually the North of England (Manchester and Leeds). It is proving difficult to make the business case precisely because the full effects of the investment are unknown ${ }^{16}$, and when applying the CDF it is just as difficult to know where to allocate the benefits and disbenefits of such a scheme; in short, will they concentrate in London, the southeast more generally, the three regional cities or the UK more generally. This argument extends to all other aspects of the performance of a city, meaning that the parameters vary both temporally and spatially and boundaries of influence are difficult to draw. 

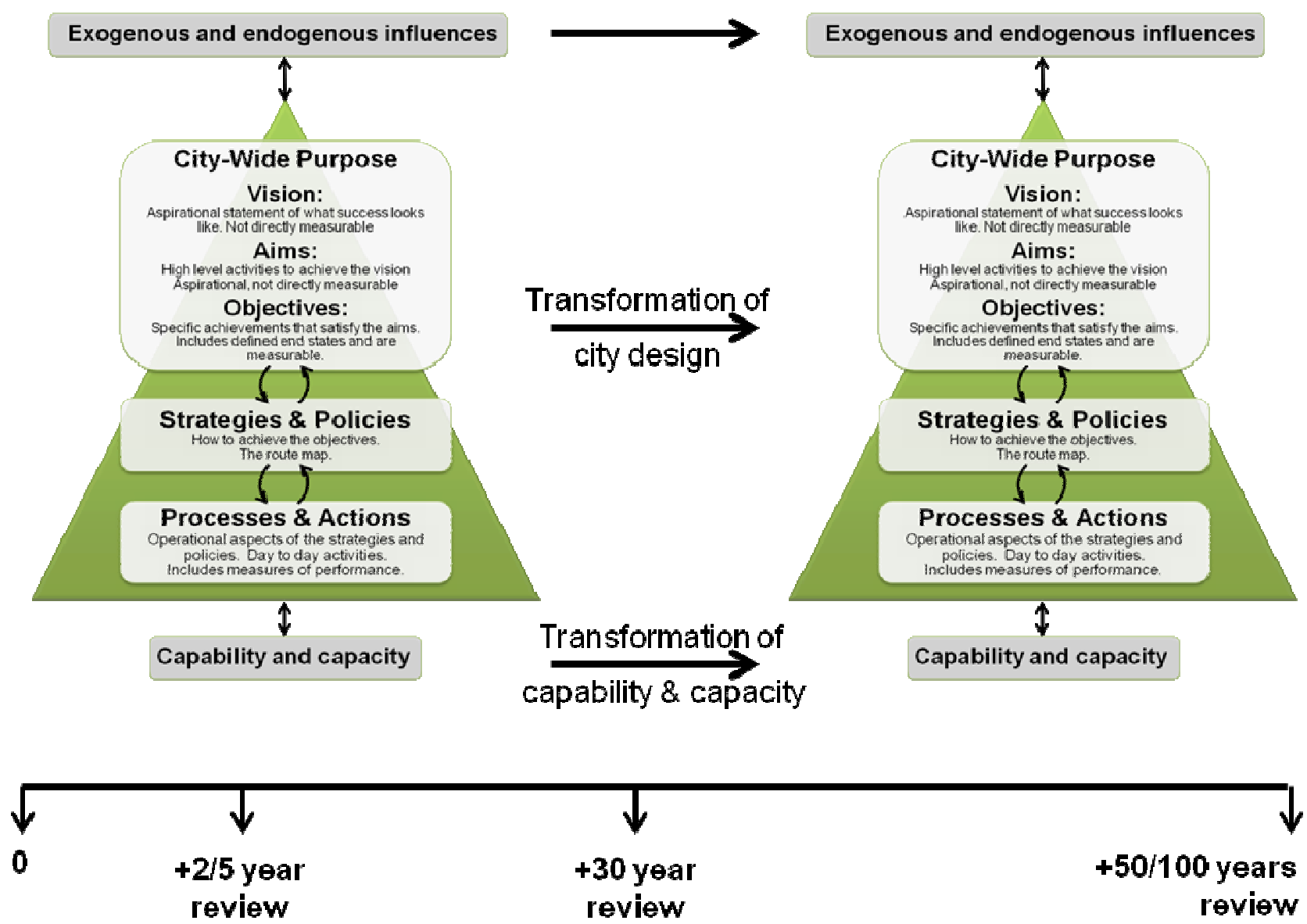

Figure 4. City Design Framework Roadmap, adapted from Foundation for Global Education and Research $^{17}$

\section{Conclusion}

This paper has described a framework for measuring the performance of a city and enabling the impact of interventions to be deduced. In turn, it provides a roadmap (or at least the means to create a roadmap) for improving the planning of infrastructure (and other) investments for the purpose of creating liveable cities. Further research is on-going to understand the full economic, social and environmental effects of infrastructure investments, and where their impacts lay both spatially and temporally. The aid to planning lies in informing the city's exogenous and endogenous influences, the various levels of the City Strategic Management Hierarchy (and the first, second and third order relationships that connect them), the city's capabilities and capacities, as well as how these will change over time. Moreover, in addition to strengthening the linkages upwards and downwards in the space between vision and processes and actions, it provides a vehicle to explore the potential impacts, both positive and negative, of radical change and provide a very real possibility that it might be adopted where the benefits outweigh the disbenefits. 


\section{Acknowledgements}

The authors wish to thank the UK Engineering and Physical Sciences Research Council (EPSRC) for their support under grant number EP/J017698/1.

\section{References}

${ }^{1}$ Liveable Cities, Liveable Cities: Transforming the Engineering of Cities for Global and Societal Wellbeing, 2013, URL: www.liveablecities.org.uk

${ }^{2}$ Merriam-Webster, Incorporated, Liveability, 2013, URL: http://www.merriamwebster.com/dictionary/liveability

${ }^{3}$ The Free Dictionary by Farlex, Liveable, 2013.

${ }^{4}$ Swannell, J. (Editor), The Little Oxford Dictionary, 6th edition, Oxford: Clarendon Press, 1986.

${ }^{5}$ Manser, M., O’Neill, M., and O’Donoghue, E. (Editors.), The Chambers Thesaurus, Edinburgh: Chambers Harrap Publishers Ltd, 2013.

${ }^{6}$ The Economist Intelligence Unit, The Liveabililty Ranking and Overview, August 2012.

${ }^{7}$ Parakatil, S., Defining 'Quality of Living', 2013.

${ }^{8}$ Ministry of Foreign Affairs, Denmark. Monocle: Copenhagen is the Most Livable City in the World, 2013.

${ }^{9}$ Portney, K. E., Taking Sustainable Cities Seriously: economic development, the environment, and quality of life in American cities, Cambridge, Massachusetts: MIT Press, 2003.

${ }^{10}$ Bordum, A., "The strategic balance in a change management perspective," Society and Business Review, Vol. 5, No. 3, 2010, pp. $245-258$.

http://dx.doi.org/10.1108/17465681011079473

${ }^{11}$ Bititci, U. S., Carrie, A. S., and McDevitt, L., "Integrated performance measurement systems: a development guide," International Journal of Operations and Production Management, Vol. 17, No. 5, 1997, pp. 522 - 534.

http://dx.doi.org/10.1108/01443579710167230

${ }^{12}$ Gallery, M. E., and Waters, S., "The Development of Consensus Guidelines for Strategic Planning in Associations", Journal of Association Leadership, Summer, 2008.

${ }^{13}$ Turner, J. R., and Müller, R., "On the nature of the project as a temporary organization," International Journal of Project Management, Vol. 21, No. 1, 2003, pp. 1-8.

http://dx.doi.org/10.1016/S0263-7863(02)00020-0

${ }^{14}$ The Cabinet Office, Strategic Framework and Policy Statement on Improving the Resilience of Critical Infrastructure to Disruption from Natural Hazards, London: Cabinet Office, 2010.

${ }^{15}$ Allen, E., Cleansing the City: Sanitary Geographies in Victorian London, Ohio University Press, 2008.

${ }^{16}$ Department for Transport, The Economic Case for HS2: Value for Money Statement, Department for Transport: London, 2012.

${ }^{17}$ Foundation for Global Education and Research, Father of strategic management, 2013. 